\title{
Plant community recovery from intense deer grazing depends on reduction of graminoids and the time after exclosure installation in a semi-natural grassland
}

\author{
Chiaki Otsu ${ }^{\text {Corresp., } 1}{ }^{,}$Hayato Iijima ${ }^{2}$, Takuo Ngaike $^{1}$ \\ 1 Department of Forest Research, Yamanashi Forest Research Institute, Fujikawa, Yamanashi, Japan \\ 2 Wildlife biology, Forestry and Forest Products Research Institute, Tsukuba, Japan \\ Corresponding Author: Chiaki Otsu \\ Email address: shiroiwayagi105@gmail.com
}

Exclosures that exclude large herbivores are effective tools for the protection and restoration of grazed plant communities. However, previous studies have showed that the installation of an exclosure does not ensure plant community recovery. Our study aimed to determine the effects of the domination of unpalatable plants and the timing of exclosure installation on the plant community recovery process in montane grassland overgrazed by sika deer (Cervus nippon) in Japan. In this study we compared plant species composition and their cover with inside and outside exclosures installed at different times.

Furthermore, we also compared them with those in 1981, when density of sika deer was very low. We used quadrats inside and outside fenced areas established in 2010 and 2011 to record both the cover and the height of species in each quadrat between 2011 and 2015. Plant cover, with the exception of graminoid species, increased in later years in all treatments. Non-metric multidimensional scaling (NMDS) plots showed significantly differentiated treatment trends. The species composition within the 2010 fenced area gradually shifted to greater similarity with the species composition reported in 1981 . The plant community in the 2011 fenced area was slower to recover. Compositions of plant communities outside the fenced areas hardly changed from 2011 to 2015 . Chao's dissimilarity index decreased over time between the plant community surveyed between 2011 and 2015 and the past plant community in 1981 within the exclosures, and was higher in the 2011 fenced area than in the 2010 fenced area. In conclusion, we show that the reduction of graminoids and the time after exclosure installation were important for plant community recovery from deer grazing damage. A delay in exclosure installation of one year could result in a delay in plant community recovery of more than one year. 
1 Plant community recovery from intense deer grazing depends on reduction of

2 graminoids and the time after exclosure installation in a semi-natural grassland

3

4 Chiaki Otsu $^{1 *}$, Hayato Iijima ${ }^{2}$, Takuo Nagaike ${ }^{1}$

5

$6 \quad{ }^{1}$ Department of Forest Research, Yamanashi Forest Research Institute, Fujikawa, Yamanashi, 7 Japan

$8{ }^{2}$ Wildlife biology, Forestry and Forest Products Research Institute, Matsunosato, Tsukuba,

9 Ibaraki, Japan

10

11 Corresponding Author:

12 Chiaki Otsu $^{1}$

13 Address: 2290-1 Saishoji, Fujikawa, Yamanashi 400-0502, Japan

14 Email address: shiroiwayagi105@gmail.com

15 


\section{Abstract}

17 Exclosures that exclude large herbivores are effective tools for the protection and restoration of 18 grazed plant communities. However, previous studies have showed that the installation of an 19 exclosure does not ensure plant community recovery. Our study aimed to determine the effects 20 of the domination of unpalatable plants and the timing of exclosure installation on the plant 21 community recovery process in montane grassland overgrazed by sika deer (Cervus nippon) in 22 Japan. In this study we compared plant species composition and their cover with inside and 23 outside exclosures installed at different times. Furthermore, we also compared them with those in 24 1981, when density of sika deer was very low. We used quadrats inside and outside fenced areas established in 2010 and 2011 to record both the cover and the height of species in each quadrat between 2011 and 2015. Plant cover, with the exception of graminoid species, increased in later years in all treatments. Non-metric multidimensional scaling (NMDS) plots showed significantly differentiated treatment trends. The species composition within the 2010 fenced area gradually shifted to greater similarity with the species composition reported in 1981 . The plant community in the 2011 fenced area was slower to recover. Compositions of plant communities outside the fenced areas hardly changed from 2011 to 2015. Chao's dissimilarity index decreased over time between the plant community surveyed between 2011 and 2015 and the past plant community in 1981 within the exclosures, and was higher in the 2011 fenced area than in the 2010 fenced area. In conclusion, we show that the reduction of graminoids and the time after exclosure installation were important for plant community recovery from deer grazing damage. A delay in exclosure installation of one year could result in a delay in plant community recovery of more than one year.

\section{Introduction}

Overgrazing by large herbivore populations exceeding the land-carrying capacity can reduce plant species diversity and the regeneration of tree species (Rooney \& Waller, 2003; Côté et al., 2004). Fences that exclude large herbivores (exclosures) can increase the diversity of plant species within the exclosure (Rooney 2009; Yayneshet, Eik \& Moe, 2009), their chances of reproduction (Shelton \& Inouye, 1995; Cooper, 2006), their biomass (Bråthen \& Oksanen, 2001; Yayneshet et al., 2009), and their heights (Iijima \& Otsu, 2018) in some systems in several geographical regions. These previous studies may suggest that plant communities damaged by deer will recover to past compositions following exclosure installation and, as such, exclosures may be essential for the protection and restoration of plant communities.

However, in some cases it has been noted that exclosure installation has only a limited desirable effect on forest understory vegetation restoration (Tanentzap, Kirby \& Goldberg, 2012). Severe disturbances (i.e., high intensity, and prolonged grazing and trampling by deer) caused by the delay in the decrease or exclusion of deer may cause irreversible changes in ecosystems and shift them to "alternate (stable) states" (Beisner, Haydon \& Cuddington, 2003; Suding, Gross \& Houseman, 2004; Tanentzap, Kirby \& Goldberg, 2012). More specifically, consumption of plant biomass, reduction of propagules, and formation of recalcitrant 
56

57

58

59

60

61

62

63

64

65

66

67

68

69

70

71

72

73

74

75

76

77

78

79

80

81

82

83

84

85

86

87

88

89

90

91

92

93

94

95

understories are suggested as the factors in the delay of plant community recovery after deer density reduction (Tanentzap, Kirby \& Goldberg, 2012). For example, Tamura (2016) surveyed the plant community and soil seed bank of a forest understory within and outside exclosures after the reduction of deer density, showing that the plant community did not recover outside exclosures even though deer density had decreased. It is believed that the reason for this recovery failure was a lack of soil seed banks of deer palatable plants outside the exclosure. Therefore, early installation of exclosures may be important to avoid depletion of seed banks or propagules. In addition, the study by Nuttle, Ristau \& Royo (2014) showed that the dominance of unpalatable plant species interfered with recovery of plant communities in a forest understory at least 20 years after deer exclusion. The dominance of unpalatable species under intense grazing is broadly observed in grasslands and forests in temperate (Beguin, Pothier \& Côté, 2011), boreal (Takatsuki 2009; Nuttle, Ristau \& Royo, 2014), and arid zones (Valone et al., 2002). Therefore, the dominance of unpalatable plant species is also expected to be important for the success or failure of plant community recovery after exclosure installation.

Previous studies on the effects of exclosure installation on plant community recovery have compared species composition (Valone et al., 2002) and the densities of forb taxa (Tamura, 2010) among fenced-off areas established at different times. However, these studies examined restoration at sites that had already been disturbed by herbivores, and may therefore have overlooked the legacy of grazing effects on the plant communities. Restoration success should be measured in relation to the vegetation in reference sites at which the reconstruction effort is aimed (SER, 2004). The reference sites should contain primary vegetation that has not been subjected to overgrazing by large herbivores.

Many deer palatable species like forbs inhabit semi-natural grasslands (Cousins \& Lindborg, 2008; Otsu et al., 2017), which have been maintained by mowing and burning. The sika deer (Cervus nippon) population, which has increased since the 1980s in Japan, has caused a decrease due to grazing in grassland specialist species in grassland communities (Otsu, Hoshino \& Matsuzaki, 2011). Furthermore, the total grassland area, which had covered $50 \%$ to $70 \%$ of Japan's total land area in the 1650s, decreased to less than $1 \%$ by the early 2000s (Ogura, 2006) because of abandonment and conversion in land use, which are common with European regions (Steiner et al., 2016). Such grassland decrease in Japan had never been occurred during past 100000 years (Yamaura et al., 2019). Therefore, the protection of grassland specialist species in semi-natural grasslands from deer herbivory has become an increasingly urgent issue (Okubo, 2002).

The aim of this study was to determine what factors relate to the plant community recovery process after the installation of deer exclosures in a semi-natural grassland damaged by deer. We focused on the effects of timing of exclosure installation and the dominance of unpalatable species by surveying the cover of plants in a semi-natural grassland in Japan where deer exclosures were installed, and comparing the observed species composition with the known past plant community, i.e., that hardly affected by sika deer sampled in 1981. Using our findings, we put forward recommendations for restoration projects in semi-natural grasslands. 
96

97

98

99

100

101

102

103

104

105

106

107

108

109

110

111

112

113

114

115

116

117

118

119

120

121

122

123

124

125

126

127

128

129

130

131

132

133

134

135

\section{Materials \& Methods Study site}

The study site was at 2,003 m elevation on Mt. Kushigata (summit elevation: 2,053 m above sea level [a.s.1.]; Yamanashi Prefecture, Central Japan) in a cool-temperate zone where the mean annual precipitation and temperature (at the nearest meteorological station [Oizumi, $867 \mathrm{~m}$ a.s.1.]) were $c a .1,140 \mathrm{~mm}$ and $10.7^{\circ} \mathrm{C}$, respectively. The mean annual temperature at the summit of Mt. Kushigata was $c a .3 .5^{\circ} \mathrm{C}$.

Patches (5.5 ha) of semi-natural grassland at the site were previously dominated by Iris sanguinea (Table $\mathrm{S} 1$ ). The patches were surrounded by Larix kaempferiand plantations and fragmented natural forests dominated by subalpine coniferous stands containing Abies veitchii and Tsuga diversifolia. In the past, these semi-natural grasslands were mown by the local populace (J. Imakiire, personal communication), but had been abandoned for more than 35 years at the time of this study (M. Ishihara, personal communication). This grassland is famous as a place to view various wild flowers and owned by Yamanashi prefecture (our institution). In this area, sika deer density in 2010 had been linearly increasing from $7.6 / \mathrm{km}^{2}$ in 2005 to $21.5 / \mathrm{km}^{2}$ (Iijima \& Ueno, 2016). Thereafter, the mean density \pm standard deviation of sika deer in the period 2011-2014 was $22.8 \pm 0.5 / \mathrm{km}^{2}$ (Iijima \& Ueno, 2016).

\section{Field survey}

In the summer of 1981, the Science Club at Koma High School examined the vegetation in the grassland patch we studied (Koma High School, 1986). The club deployed 24 precisely measured $1 \times 1 \mathrm{~m}$ quadrats in a grassland typically dominated by $I$. sanguinea and sampled the vegetation inside the frames using Braun-Blanquet phytosociological procedures (BraunBlanquet, 1964). The identification of species was checked by a professional researcher (E. Ohkubo). Deer distribution had not been confirmed in 1979, but was confirmed in 2003 in this area (Biodiversity Center of Japan, 2004), although these quadrats were not fenced at the time. Thus, we considered the species composition in 1981 to be representative of the vegetation before the beginning of heavy sika deer grazing.

In October 2010, the Minami-Alps City Government installed a $60 \times 60 \mathrm{~m}$ fence, which reached a height of $2 \mathrm{~m}$, to protect vegetation from deer grazing. The following year, the Yamanashi Forest Research Institute installed a $20 \times 25 \mathrm{~m}$ fence adjacent to the first fence because of heavy grazing at the site. Both fences were located on open and homogenous land with a 20 degree slope and were about $10 \mathrm{~m}$ from the edge of the forest, so that topographical conditions were similar for both fenced areas. We studied the vegetation in three treatments: (i) inside the fence installed in 2010 (hereafter, fence 2010); (ii) inside the fence installed in 2011 (hereafter, fence 2011); and (iii) outside both fences (hereafter, outside). We deployed 22, $1 \times 1$ m quadrats inside the exclosures (fence 2010, 10 quadrats; fence 2011, 12 quadrats), and 10 quadrats were established outside. All of the treatments were located within $20-30 \mathrm{~m}$ of the quadrats deployed in the Koma High School study. 
136

137

138

139

140

141

142

143

144

145

146

147

148

149

150

151

152

153

154

155

156

157

158

159

160

161

162

163

164

165

166

167

168

169

170

171

172

173

174

We recorded the cover and the maximum height of species occurring in each of the quadrats in August of each year from 2011 to 2015 (five years total). Cover was evaluated using the Braun-Blanquet scale(Braun-Blanquet, 1964).

\section{Statistical analysis}

The Koma High School study recorded only species with a cover score of $\geqq 1$ on the Braun-Blanquet scale (Braun-Blanquet, 1964). We adopted the same procedure for this analysis to enable good comparison between past and present conditions. Responses to grazing differ among life form groups (Sternberg et al., 2000; Dupré \& Diekmann, 2001). In particular, graminoids were suggested to be tolerant to grazing in many studies (Pellerin, Huot \& Côté, 2006; Mysterud, 2006; Rooney, 2009). Accordingly, we categorized species identified in the quadrats into five life form groups: graminoids; monocots other than graminoids (hereafter, monocots); dicot herbs (hereafter, dicots); ferns; and woody plants.

Firstly, we used a cumulative link mixed model (CLMM) with a logit link function to examine the effects of treatments (i.e., fence 2010, fence 2011, and outside) the year after exclosure installation (hereafter, the protected year), the life form of each species, and the interaction between the life form of each species and the protected year on species cover. The CLMM included each site and each year as random effects. The coefficients of the treatment and the life form were estimated when the coefficients of fence 2010 and graminoid were set as 0 . The CLMM was performed by the "ordinal" package (Christensen, 2018) of software R (R Core Team, 2018).

Next, we examined the differences in plant community composition among treatments. We calculated the Chao dissimilarity index (Chao et al., 2005) to compare species composition in 1981 with data for the years from 2011 to 2015 across the combination of quadrats in each of the three areas. The index was used as a measure of the degree of species composition restoration. The Chao dissimilarity index was designed to consider unseen shared species using (replicated) abundance-based sampling data (Chao et al., 2005) and was therefore considered appropriate for our datasets, which excluded species with a cover score of $<1$ on the BraunBlanquet scale, assumed as unseen rare species. We examined the ordination diagrams to evaluate species composition in 1981 and from 2011 to 2015 by non-metric multidimensional scaling (NMDS) using the Chao dissimilarity index to compare changes in species composition between treatments. NMDS was performed using the "vegan" package (Oksanen et al., 2018) of software R (R Core Team, 2018).

We examined the effects of the treatments, the protected year, and the mean cover of graminoids on the Chao dissimilarity index by a generalized linear mixed model (GLMM) with beta error distribution and a logit link function. The GLMM included each site and each year as random effects. The coefficient of treatment was estimated when the coefficient of fence 2010 was set as 0. The GLMM was performed by the "glmmTMB" package (Brooks et al., 2017) of software R (R Core Team, 2018). 
175

176

177

178

179

180

181

182

183

184

185

186

187

188

189

190

191

192

193

194

195

196

197

198

199

200

201

202

203

204

205

206

207

208

209

210

211

212

213

214

For the CLMM and GLMM, we calculated the Akaike information criterion (AIC) with all possible combinations of explanatory variables. We considered the model with the lowest AIC as the most predictive model and with the explanatory variable(s) with significant effect(s) on the response variable.

\section{Results}

The past and recent plant community

We found 56 plant species ( 37 dicots, 11 graminoids, 3 monocots, 2 ferns, and 3 woody plants) in all quadrats (Table S1). The total number of species identified in 1981 was 24 (Table $\mathrm{S} 1$ ), and the plant community was characterized by the dominance of a monocot (Iris sanguinea) and of dicots (Serratula coronata var insularis, Geranium eriostemon var reinii, Veronicastrum sibiricum, and Senecio cannabifolius). In particular, the monocot Iris sanguinea was highly dominant (Table S1).

The mean cover of each life form group differed among treatments and years (Fig. 1). Generally, in 2011 graminoids dominated regardless of treatments, and the plant community in 2011 differed greatly from the plant community observed in 1981. Beginning in 2012, monocots, ferns, and woody plants emerged in fence 2010 . Monocots and woody plants also emerged in fence 2011 from 2014 onward. In contrast, quadrats of the outside treatment were dominated by graminoids and dicots, and no other life form species was noted during the study period. CLMM analysis on the cover of plants with the lowest AIC was calculated for the protected year, the life form, and the interaction between the protected year and the life form (Table 1, Table S2). The results suggest that the effect of treatment on cover was not significant. Graminoid cover was the highest among the life form groups (Table 1). Plant cover of all life form types, except graminoids, increased within the exclosures over time. The coefficients of the interaction term between the protected year and the life form were positive with the exception of graminoids (Table 1).

\section{Changes in species composition and community structure}

NMDS showed remarkably different trends in plant community composition among treatments (Fig. 2). Species composition in fence 2010 gradually became more similar to composition recorded in 1981 (Fig. 2). The species composition in fence 2011 also became similar to the composition of 1981, but recovery was slower in fence 2011 than in fence 2010 (Fig. 2). The species composition in the outside treatment remained mostly unchanged from 2011 to 2015 (Fig. 2).

The trend of plant community change was reflected in the dissimilarity indices. Dissimilarity indices of all treatments were high in 2011 (Fig. 3). However, the dissimilarity index of fence 2010 tended to decrease each year, while the dissimilarity index of fence 2011 remained unchanged at a high level until 2013 and then decreased after 2014. In 2014, monocots and woody plants recovered in fence 2011 (Table 1, Fig. 1). The indices computed from samples outside the exclosures rarely changed during the study period (Fig. 3). The GLMM of the 
215 dissimilarity index with the lowest AIC contained all explanatory variables (Table S3). The 216 dissimilarity index was lower in fence 2010 than in both fence 2011 and outside (Table 2).

217 Furthermore, the dissimilarity index decreased over time with protected year and a decrease in 218 mean cover of graminoids (Table 2).

219 Forb species (i.e., dicots and monocots) were not as tall as the graminoids in many quadrats 220 regardless of the treatments in 2011 (Fig. 4), and forb species in outside remained shorter than 221 the graminoids in 2015 (Fig. 4). However, in most of the quadrats of fences 2010 and 2011, the 222 heights of the forb species exceeded those of the graminoids in 2015 (Fig. 4).

223

224

225

226

227

228

229

230

231

232

233

234

235

236

237

238

239

240

241

242

243

244

245

246

247

248

249

250

251

252

253

254

\section{Discussion}

\section{Different response of cover to exclosure installation among life form groups}

Exclusion of large herbivores from areas can alter plant cover (e.g., decrease the abundance of graminoids and increase the abundance of forbs [Austrheim et al., 2008; Rooney, 2009]). In this study, we also found that plant cover of all life form groups except graminoids increased with time after exclosure (Table 1). The domination of graminoids outside the exclosure (Fig. 1) reflects the tolerance of graminoids to deer grazing. The short stature, intercalary meristems, high shoot densities, and capacity for compensatory growth enable graminoids to tolerate herbivory, giving them a competitive advantage over forb species in heavily grazed environments (Rooney, 2009; Iijima \& Otsu 2018). Then, when grazing pressure is removed, forb species can regenerate from underground organs or seeds that are scattered from the surrounding habitat.

It should be noted that some forb species also existed and increased in cover in outside (Table S1) where plants are exposed to deer grazing. Protection by abundant graminoids may be one of the factors that the some forb species could survive in outside. It is known that unpalatable or grazer tolerant species cover and protect neighbouring palatable species from herbivores (Milchunas \& Noy-Meir, 2002; Callaway et al., 2005). Graminoids are very tolerant to grazing (Pellerin et al., 2006; Mysterud, 2006; Rooney, 2009), which could explain their high abundance in outside (Table 1). In turn, the high abundance of graminoids in outside may have facilitated survival of forb species and their colonization outside the fences.

Furthermore, some forbs may be protected from deer grazing by their diminutive size (Bullock et al., 2001; Diaz, Noy-Meir \& Cabido, 2001; Lavorel, McIntyre \& Grigulis, 2009) or rosette form (Kahmen, Poschlod \& Schreiber, 2002; Lavorel, McIntyre \& Grigulis , 2009; de Villalobos \& Zalba, 2010). We found that species either not occurring or occurring at low abundance in the original vegetation (diminutive species, such as Potentilla freyniana, and rosette species such as Senecio flammeus var glabrifolius) were frequent in outside (Table S1).

\section{Determining factors for the plant community recovery process}

Plant community recovery was inhibited by high cover of graminoids (Table 2). Although unpalatable plants cover palatable plants, as stated above, the facilitative effect would have been partly counterbalanced by a negative competitive interaction, whereby the graminoids 
255

256

257

258

259

260

261

262

263

264

265

266

267

268

269

270

271

272

273

274

275

276

277

278

279

280

281

282

283

284

285

286

287

288

289

290

291

292

293

would have shaded the forbs and prevented them from achieving high abundances. In fact, the heights of forbs were lower than those of graminoids in outside, while in 2015 the heights of forbs were higher than those of graminoids in enclosed areas (Fig. 4). Forb species in outside did not appear to contribute significantly to whole plant community recovery, suggesting that the domination of unpalatable plants can delay plant community recovery.

Although the dominance of browsing-tolerant species could slow or halt plant community recovery (Royo, Stout, deCalesta \& Pierson, 2010; Nuttle, Ristau \& Royo, 2014), in this study we observed that plant community recovery progressed over time after exclosure installation (Table 2). At the beginning of this survey there were still other plant species, such as monocots and dicots, in our research site (i.e., 2011, Fig. 1). The remaining palatable species at fence installation are suggested to be important for the successful recovery of the plant community after exclosure installation. Furthermore, although dicots did not exist in fence 2011 until 2013, dicots recovered in fence 2011 in 2014 (Fig. 1), resulting in a decreased dissimilarity index (Fig. 3).

Because we considered the effect of protected year and the random effect of each quadrat location simultaneously, early installation of exclosures may also be important to plant community recovery. The restoration of monocots including I. sanguinea, but excluding graminoids, seemed to be largely precluded by a one year delay in exclosure installation (Fig. 1; Table S1). Forbs (including monocots) are relatively palatable to sika deer (Takatsuki 1986), and geophytes - such as members of Liliaceae, Orchidaceae, and Iridaceae - are vulnerable to grazing (Dupré \& Diekmann, 2001; Dorrough \& Scroggie, 2008; Fernández-Lugo et al., 2013). In fact, when we set fence 2011, we observed heavy grazing at the site where the fence was going to be set (C. Otsu, 2011, personal observation). Thus, both sika deer preferences for monocots other than graminoids and the poor anti-grazer defences of these plants may make their recovery difficult. At our study site, delays in the restoration of $I$. sanguinea (the most abundant species before the increase of the sika deer population) may also have caused delays in the restoration of overall community species composition (Nagaike, Ohkubo \& Hirose, 2014).

\section{Conclusions}

Our study showed that plant community recovery from deer grazing damage depends on the reduction of graminoids and the time after exclosure installation in a semi-natural grassland. Specifically, a delay in exclosure installation of one year could result in a delay in plant community recovery of more than one year. Therefore, early fence installation is recommended for plant community recovery.

\section{References}

Austrheim G, Mysterud A, Pedersen B, Halvorsen R, Hassel K, Evju M. 2008. Large scale experimental effects of three levels of sheep densities on an alpine ecosystem. Oikos 117:837-846. 
294 Biodiversty Center of Japan. 2004. Natural Environmental Information GIS. Available at 295 http://www.biodic.go.jp/trialSystem/top_en.html (accessed 23 July 2019).

296 Beguin J, Pothier D, Côté SD. 2011. Deer browsing and soil disturbance induce cascading effects 297 on plant communities: a multilevel path analysis. Ecological Applications 21:439-451.

298 Beisner BE, Haydon DT, Cuddington K. 2003. Alternative stable states in ecology. Frontiers in $299 \quad$ Ecology and the Environment 1:376-382.

300 Bråthen KA, Oksanen J. 2001. Reindeer reduce biomass of preferred plant species. Journal of 301 vegetation Science 12:473-480.

302 Braun-Blanquet J. 1964. Pflanzensociologie, 3 aufl. Wien: Springer.

303

304

305

306

307

308

309

310

311

312

313

314

315

316

317

318

319

320

321

322

323

324

325

326

327

328

329

330

331

332

333

Brooks ME, Kristensen K, van Benthem KJ, Magnusson A, Berg CW, Nielsen A, Skaug HJ, Mächler M, Bolker BM. 2017. glmmTMB balances speed and flexibility among packages for zero-inflated generalized linear mixed modeling. The R journal, 9:378-400.

Bullock JM, Franklin J, Stevenson MJ, Silvertown J, Coulson SJ, Gregory SJ, Tofts R. 2001. A plant trait analysis of responses to grazing in a long-term experiment. Journal of Applied Ecology, 38: 253-267.

Callaway RM, Kikodze D, Chiboshvili M, Khetsuriani L. 2005. Unpalatable plants protect neighbors from grazing and increase plant community diversity. Ecology 86:1856-1862.

Chao A, Chazdon RL, Colwell RK, Shen TJ. 2005. A new statistical approach for assessing similarity of species composition with incidence and abundance data. Ecology Letters 8:148159.

Christensen RHB 2018. Ordinal-Regression Models for Ordinal Data. R package version 2018.825. http://www.cran.r-project.org/package=ordinal/. (accessed 7 February 2019).

Cooper EJ. 2006. Reindeer grazing reduces seed and propagule bank in the High Arctic. Botany 84:1740-1752.

Côté SD, Rooney TP, Tremblay JP, Dussault C, Waller DM. 2004. Ecological impacts of deer overabundance. Annual Review of Ecology, Evolution, and Systematics 35:113-147.

Cousins SAO, Lindborg R. 2008. Remnant grassland habitats as source communities for plant diversification in agricultural landscapes. Biological Conservation, 141: 233-240.

De Villalobos AE, Zalba SM. 2010. Continuous feral horse grazing and grazing exclusion in mountain pampean grasslands in Argentina. Acta Oecologica 36:514-519.

Díaz S, Noy-Meir I, Cabido M. 2001. Can grazing response of herbaceous plants be predicted from simple vegetative traits? Journal of Applied Ecology 38:497-508.

Dorrough J, Scroggie MP. 2008. Plant responses to agricultural intensification. Journal of Applied Ecology 45:1274-1283.

Dupré C, Diekmann M. 2001. Differences in species richness and life-history traits between grazed and abandoned grasslands in southern Sweden. Ecography 24:275-286.

Fernández-Lugo S, Bermejo LA, de Nascimento L, Méndez J, Naranjo-Cigala A, Arévalo JR. 2013. Productivity: key factor affecting grazing exclusion effects on vegetation and soil. Plant Ecology 214:641-656.

Iijima H, Otsu C. 2018. The method of conserving herbaceous grassland specialists through

Peer) reviewing PDF | (2019:06:38478:2:0:NEW 20 Aug 2019) 
334

335

336

337

338

339

340

341

342

343

344

345

346

347

348

349

350

351

352

353

354

355

356

357

358

359

360

361

362

363

364

365

366

367

368

369

370

371

372

373

silvicultural activities under deer browsing pressure. Biodiversity and Conservation, 27: 2919-2930.

Iijima H, Ueno M. 2016. Spatial heterogeneity in the carrying capacity of sika deer in Japan. Journal of Mammalogy 97: 734-743.

Kahmen S, Poschlod P, Schreiber KF. 2002. Conservation management of calcareous grasslands. Changes in plant species composition and response of functional traits during 25 years. Biological Conservation 104:319-328.

Koma High School. 1986. Iris sanguinea on Mt. Kushigata. Yamanashi: Koma High School (in Japanese).

Lavorel S, McIntyre S, Grigulis K. 1999. Plant response to disturbance in a Mediterranean grassland: How many functional groups? Journal of Vegetation Science 10:661-672.

Milchunas DG, Noy-Meir I. 2002. Grazing refuges, external avoidance of herbivory and plant diversity. Oikos 99:113-130.

Mysterud A. 2006. The concept of overgrazing and its role in management of large herbivores. Wildlife Biology 12:129-141.

Nagaike T, Ohkubo E \& Hirose K. 2014. Vegetation recovery in response to the exclusion of grazing by sika deer (Cervus nippon) in seminatural grassland on Mt. Kushigata, Japan. ISRN Biodiversity, 2014.

Nuttle T, Ristau TE, Royo AA. 2014. Long - term biological legacies of herbivore density in a landscape - scale experiment: forest understoreys reflect past deer density treatments for at least 20 years. Journal of Ecology, 102: 221-228.

Ogura J. 2006. Changes of grassland area in Japan. Bulletins of Kyoto Seika University 30:160172 (in Japanese with English abstract).

Oksanen J, Blanchet FG, Friendly M, Kindt R, Legendre P, McGlinn D, Minchin PR, O'Hara RB, Simpson GL, Solymos P, Stevens MHH, Szoecs E, Wagner H. 2018. vegan: Community Ecology Package. R package version 2.5-2. https:/CRAN.Rproject.org/package=vegan. (accessed 7 February 2019).

Okubo K. 2002. The present state in the study of biological diversity on semi-natural grassland in Japan. Grassland Science 48:268-276 (in Japanese with English abstract).

Otsu C, Hoshino Y, Matsuzaki A. 2011. Impacts of the sika deer on montane and subalpine grasslands in Chichibu-Tama-Kai National Park and surrounds, central Japan. Vegetation Science 28:1-17 (in Japanese with English abstract).

Otsu C, Iijima H, Nagaike T, Hoshino Y. 2017. Evidence of extinction debt through the survival and colonization of each species in semi - natural grasslands. Journal of Vegetation Science, 28: 464-474.

Pellerin S, Huot J, Côté SD. 2006. Long-term effects of deer browsing and trampling on the vegetation of peatlands. Biological Conservation 128:316-326.

R Development Core Team. 2018. R: a language and environment for statistical computing. Vienna, Austria: R Foundation for Statistical Computing.

Rooney TP, Waller DM. 2003. Direct and indirect effects of white-tailed deer in forest

Peer) reviewing PDF | (2019:06:38478:2:0:NEW 20 Aug 2019) 
374

375

376

377

378

379

380

381

382

383

384

385

386

387

388

389

390

391

392

393

394

395

396

397

398

399

400

401

402

403

404

405

406

407

408

409

410

411

412

413

ecosystems. Forest Ecology and Management 181:165-176.

Rooney TP. 2009. High white-tailed deer densities benefit graminoids and contribute to biotic homogenization of forest ground-layer vegetation. Plant Ecology 202:103-111.

Royo AA, Stout SL, deCalesta DS, Pierson TG. 2010. Restoring forest herb communities through landscape-level deer herd reductions: Is recovery limited by legacy effects? Biological Conservation, 143: 2425-2434.

SER (Society for Ecological Restoration International Science and Policy Working Group). 2004. The SER International Primer on Ecological Restoration. Available at http//www.ser.org. (accessed 21 December 2016).

Shelton AL, Inouye RS. 1995. Effect of browsing by deer on the growth and reproductive success of Lactuca canadensis (Asteraceae). American Midland Naturalist 134:332-339.

Steiner M, Öckinger E, Karrer G, Winsa M, Jonsell M. 2016. Restoration of semi-natural grasslands, a success for phytophagous beetles (Curculionidae). Biodiversity and Conservation, 25: 3005-3022.

Sternberg M, Gutman M, Perevolotsky A, Ungar ED, Kigel J. 2000. Vegetation response to grazing management in a Mediterranean herbaceous community: a functional group approach. Journal of Applied Ecology 37:224-237.

Suding KN, Gross KL, Houseman GR. 2004. Alternative states and positive feedbacks in restoration ecology. Trends in Ecology and Evolution 19:46-53.

Takatsuki S. 2009. Effects of sika deer on vegetation in Japan: a review. Biological Conservation 142:1922-1929.

Takatsuki S. 1986. Food habits of sika deer on Mt. Goyo, northern Honshu. Ecological Research, 1:119-128.

Tamura A. 2010. Effect of time lag of establishment of deer-proof fences on the recovery of perennial herbs in a cool temperate deciduous forest diminished by sika deer browsing in the Tanzawa Mountains, central Japan. Japanese Journal of Conservation Ecology 15:255-264 (in Japanese with English abstract).

Tamura A. 2016. Potential of soil seed banks in the ecological restoration of overgrazed floor vegetation in a cool-temperate old-growth damp forest in eastern Japan. Journal of Forest Research 21:43-56.

Tanentzap AJ, Kirby KJ, Goldberg E. 2012. Slow responses of ecosystems to reductions in deer (Cervidae) populations and strategies for achieving recovery. Forest Ecology and Management, 264: 159-166.

Valone TJ, Meyer M, Brown JH, Chew RM. 2002. Timescale of perennial grass recovery in desertified arid grasslands following livestock removal. Conservation Biology 16:995-1002.

Yamaura Y, Narita A, Kusumoto Y, Nagano AJ, Tezuka A, Okamoto T, Takahara H, Nakamura F, Isagi Y, Lindenmayer D. 2019. Genomic reconstruction of 100000 -year grassland history in a forested country: population dynamics of specialist forbs. Biology Letters 15:Article ID:20180770.

Yayneshet T, Eik LO, Moe SR. 2009. The effects of exclosures in restoring degraded semi-arid 
414 vegetation in communal grazing lands in northern Ethiopia. Journal of Arid Environments $415 \quad 73: 542-549$. 
Figure 1

The change of mean coverage of each life form group in each treatment and year.

Species with a coverage score of $\geqq 1$ on the Braun-Blanquet scale were excluded from calculation. A: Fence 2010, B: Fence 2011, C: Outside.

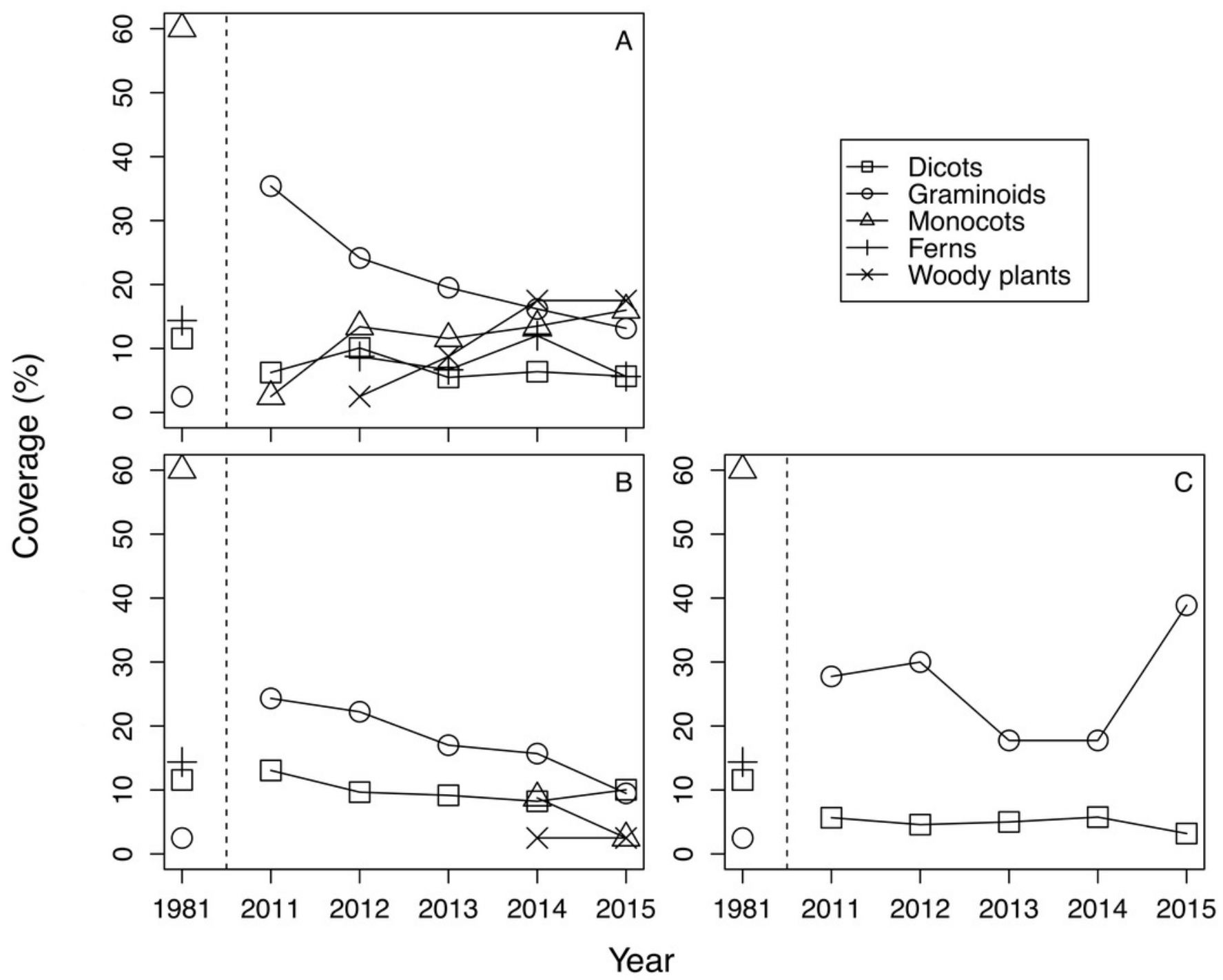


Figure 2

Non-metric Multi-dimensional Scaling (NMDS) ordination of all sample plots in a twodimensional space.

Bold arrows in each figure indicate the changes of mean scores of NMDS by each treatment from 2011 to 2015. A: 1981 and fence 2010, B: 1981 and fence 2011, C: 1981 and outside. 

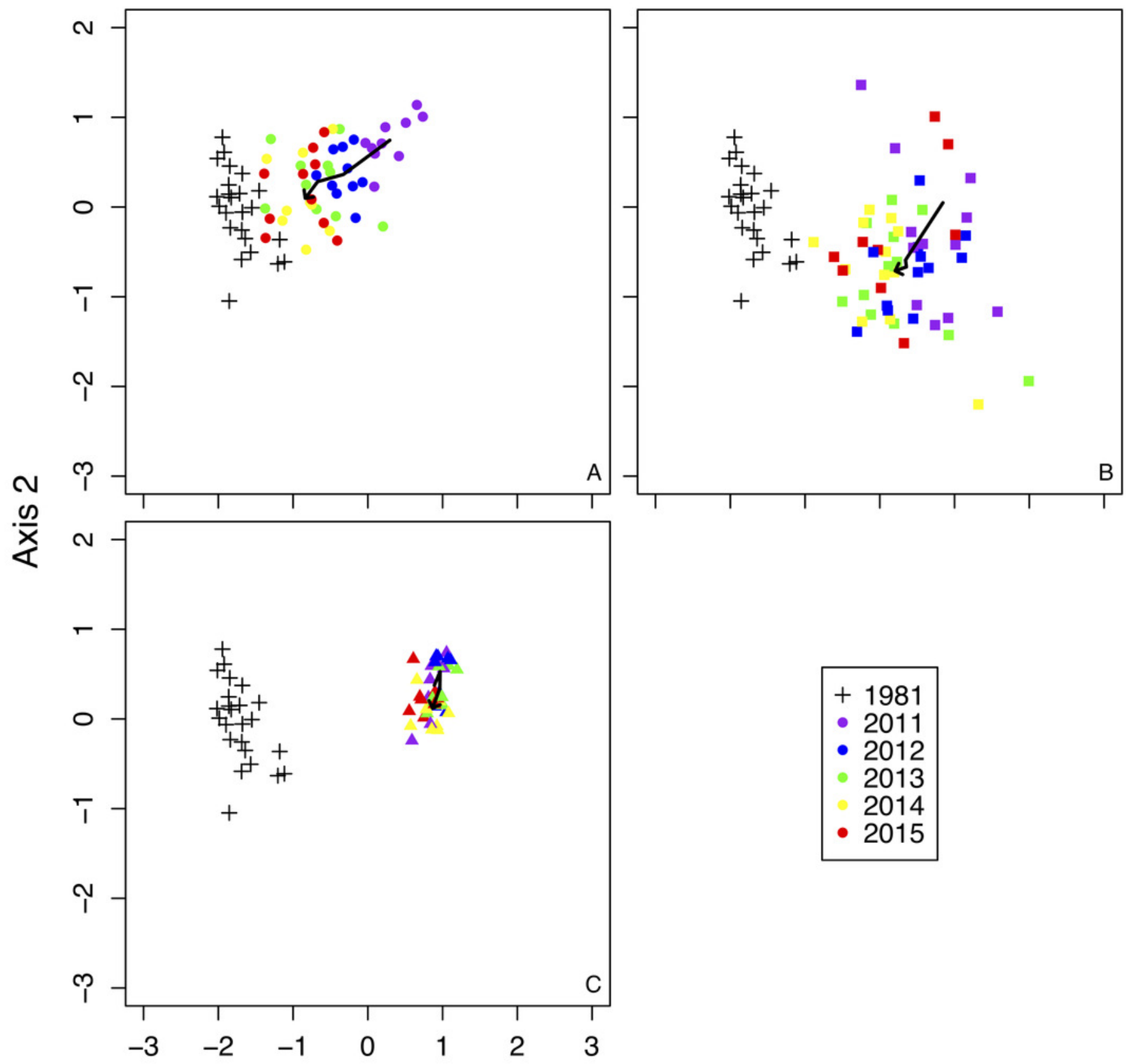

$+1981$

- 2011

- 2012

- 2013

- 2014

- 2015

Axis 1 
Figure 3

The change of dissimilarity index of each treatment and year.

Error bars indicate standard deviation of dissimilarity index.

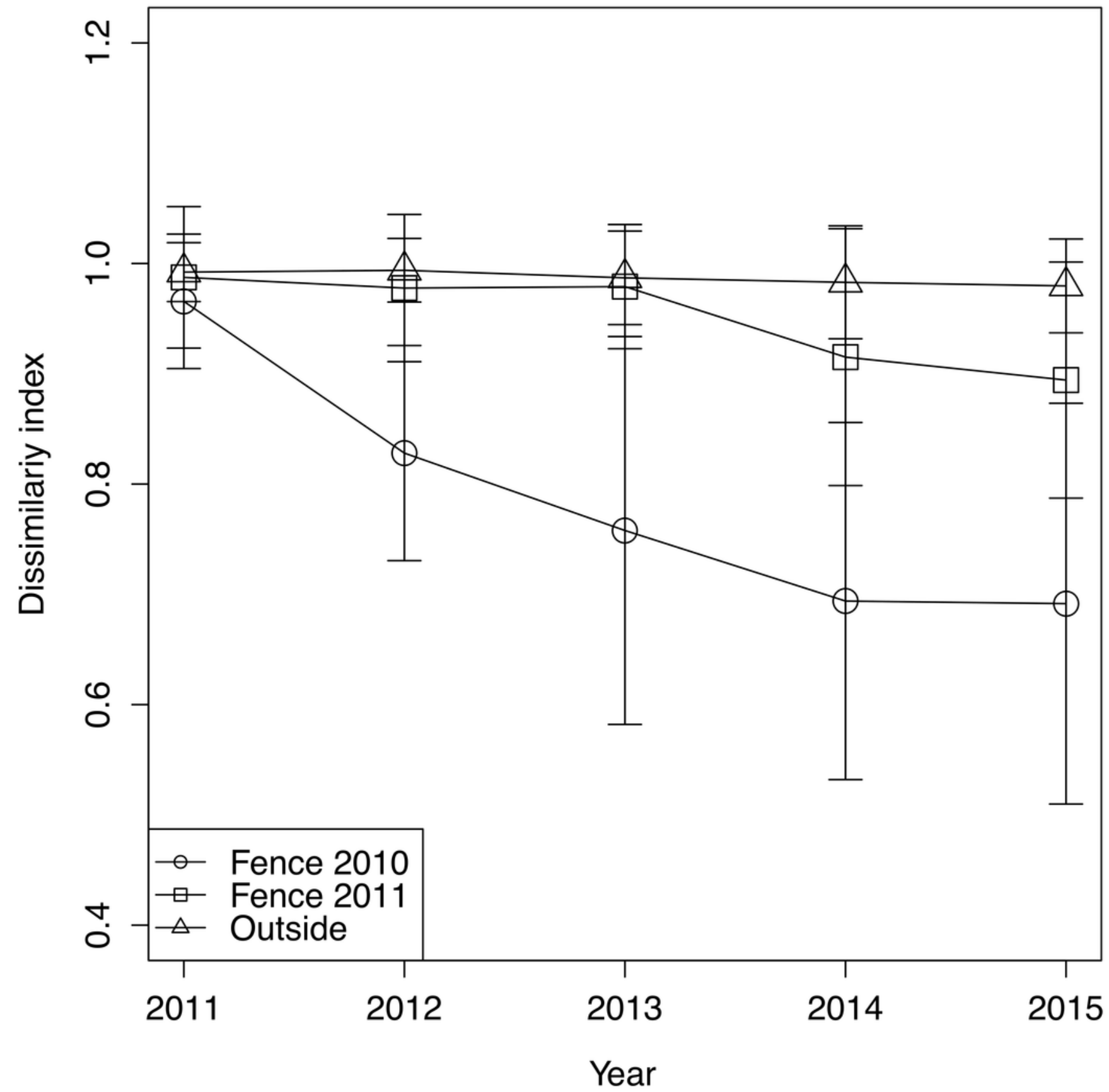


Figure 4

Relationships between the maximum heights of graminoid species and that of forb species in each quadrat in each treatment in 2011 and 2015. A: 2011, B: 2015.

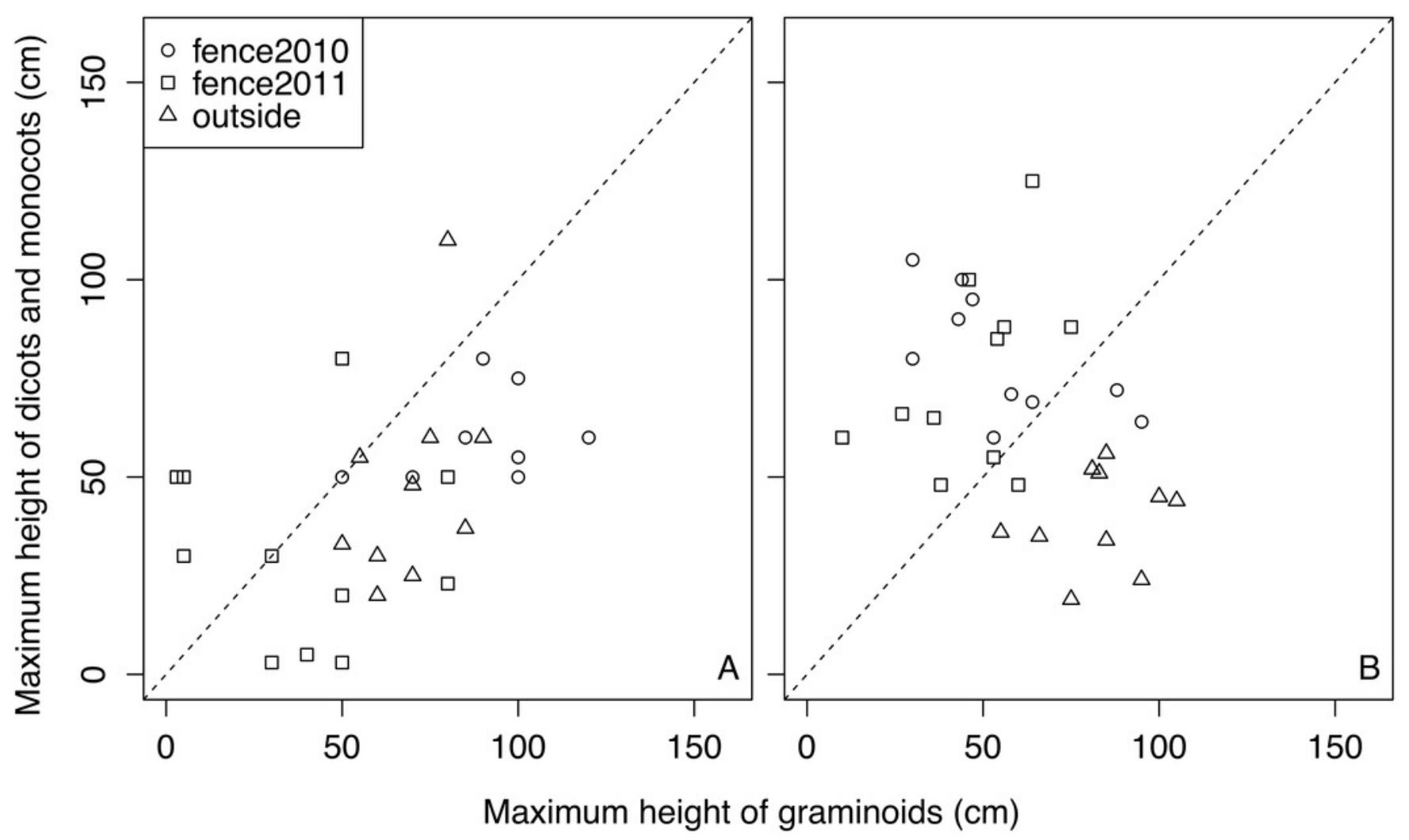




\section{Table $\mathbf{1}$ (on next page)}

Summary of CLMM with the lowest AIC.

${ }^{a}$, SE is standard error of estimated coefficients. ${ }^{b}$, The coefficients of the life form was estimated when the category of graminoid was set as reference category. In this table, only final model after model selection based on AIC is shown. Please see Table S2 for AIC of models with all possible combinations of explanatory variables. 


\begin{tabular}{lcccr}
\hline & \multicolumn{3}{c}{ Estimated coefficients } \\
& Mean & SE $^{\mathrm{a}}$ & z value & $p$ value \\
\hline The protected year & 0.329 & 0.032 & 10.175 & 0.000 \\
Life form & & & & \\
Graminoids & 1.591 & 0.127 & 12.538 & 0.000 \\
Monocots & -0.930 & 0.407 & -2.285 & 0.022 \\
Ferns & -2.422 & 0.883 & -2.744 & 0.006 \\
Woody plants & -2.490 & 0.775 & -3.213 & 0.001 \\
Interaction term & & & & \\
The protected year:Graminoids & -0.362 & 0.048 & -7.466 & 0.000 \\
The protected year:Monocots & 0.417 & 0.116 & 3.603 & 0.000 \\
The protected year:Ferns & 0.547 & 0.227 & 2.411 & 0.016 \\
The protected year:Woody plants & 0.492 & 0.202 & 2.431 & 0.015 \\
\hline
\end{tabular}




\section{Table 2 (on next page)}

Summary of GLMM with the lowest AIC.

${ }^{a}$, SE is standard error of estimated coefficients. ${ }^{b}$, The coefficient of treatment was estimated when the category of fence $\mathbf{2 0 1 0}$ was set as reference category. In this table, only final model after model selection based on AIC is shown. Please see Table S3 for AIC of models with all possible combinations of explanatory variables. 


\begin{tabular}{lrrrr}
\hline & \multicolumn{4}{c}{ Estimated coefficient } \\
& Mean & \multicolumn{1}{c}{$\mathrm{SE}^{\mathrm{a}}$} & $\mathrm{z}$ value & $p$ value \\
\hline Treatments $^{\mathrm{b}}$ & & & & \\
Fence 2011 & 1.268 & 0.135 & 9.398 & 0.000 \\
Outside & 0.749 & 0.157 & 4.772 & 0.000 \\
The protected year & -0.376 & 0.026 & -14.466 & 0.000 \\
Coverage of graminoids & 0.009 & 0.001 & 6.434 & 0.000 \\
\hline
\end{tabular}

1 